\title{
Labyrinthe
}

40 | 2013

Comme les abeilles

\section{Les Géorgiques, un manuel d'apiculture hétéroclite}

\section{Renaud Pasquier}

\section{(2) OpenEdition \\ 1 Journals}

Édition électronique

URL : http://journals.openedition.org/labyrinthe/4324

DOI : $10.4000 /$ labyrinthe.4324

ISSN : 1950-6031

Éditeur

Hermann

Édition imprimée

Date de publication : 1 mars 2013

Pagination : 105-107

ISBN : 9782705688400

\section{Référence électronique}

Renaud Pasquier, «Les Géorgiques, un manuel d'apiculture hétéroclite », Labyrinthe [En ligne],

40 | 2013, mis en ligne le 01 mars 2015, consulté le 01 mai 2019. URL : http://

journals.openedition.org/labyrinthe/4324 ; DOI : 10.4000/labyrinthe.4324

Propriété intellectuelle 


\section{Les Géorgiques, un manuel d'apiculture hétéroclite}

Renaud PAsQuier

La première partie du livre IV (du vers 1 au vers 280 , sur les 566 que compte le livre) met apparemment en œuvre le programme didactique des Géorgiques, Virgile multipliant les conseils à l'apiculteur, quant au choix du lieu pour la ruche, à la sélection des espèces, aux aliments à mettre à disposition, à la récolte du miel, mais surtout aux précautions à prendre pour éloigner les abeilles des nombreux dangers potentiels qui les menacent, qu'il s'agisse du climat trop rigoureux ou de prédateurs impitoyables: ainsi les recommandations virgiliennes sont-elles relativement lacunaires, et largement dominées par le souci de protection des abeilles, et par l'inquiétude, devant leur fragilité, pour leur bien-être et leur survie. Virgile préconise ainsi une attention, voire une délicatesse permanente à l'endroit des abeilles.

Le ton est ainsi moins souvent celui de l'exhortation ou de l'explication, que de la pure description d'une nature contemplée avec admiration, plutôt qu'exploitée pour des raisons économiques. Admiranda tibi levium spectacula rerum, «tu dois admirer le spectacle de ces petits êtres ", clame Virgile à Mécène, dans les premiers vers, en forme de préambule, de cette quatrième Géorgique. Les abeilles sont l'une des merveilles de la nature, un des échantillons de cette beauté dont le poète s'attache à élaborer l'équivalent dans ses vers, en un style très imagé et périphrastique. L'ambition principale de Virgile est d'ailleurs clamée vers 6 et 7 : la gloire, aussi grande que le sujet de ses vers est petit. Le poète s'affirme par-delà le genre qu'il a choisi, en témoigne la liberté qu'il se donne, celle des digressions, notamment, telle l'évocation, vers 125 à 147, du jardinier de Tarente, occasion d'un tableau aux vives couleurs, mais aussi portrait esquissé d'un sage en symbiose avec la nature et ses fruits.

Quand bien même les Géorgiques comportent une réelle dimension technique et didactique, il s'agit au fond pour Virgile moins d'une incitation au redressement productif agricole que d'un plaidoyer pour la terre italienne 


\section{Labyrinthe, $n^{\circ} 40$}

en elle-même, considérée comme valeur en soi. Le poème est plus moral qu'économique, ou, si l'on préfère, d'une économie reposant sur des valeurs morales : il tend, on l'a vu, vers l'exaltation d'une harmonie de la nature à préserver, donc également d'une forme de sagesse à cultiver. Ce faisant, Virgile élabore une double image de la campagne, correspondant en tout point au double objet de fantasme de ses lecteurs, ces aristocrates romains cultivés, très urbains, comme l'est majoritairement la société romaine de cette fin de siècle, guère familière de la vie des champs: la campagne, c'est donc d'abord l'espace dont on jouit, espace de beauté pour les âmes esthètes, espace de l'otium, aussi, loin des ambitions et des tumultes de l'Urbs, loin des combats et du sang des guerres civiles; mais c'est aussi le lieu d'une nostalgie patriotique, celle d'une vie rude, austère, saine et pure, celle des fondateurs d'une République qui doit tout à leur vertu terrienne. Or, on l'a vu, l'abeille appartient à ces deux fantasmes, qu'elle associe gracieusement et efficacement : objet d'émerveillement, symbole de beauté, elle est aussi un exemple et un emblème de vertu industrieuse. Enfin, et surtout, peut-être, elle est aussi vulnérable que ces deux idéaux, environnée de périls, et toujours menacée de destruction. Inquiétude pour les abeilles et à travers elles pour l'homme: celle de Virgile, alimentée par des décennies de guerres civiles, mais aussi, étrangement semblable quoique crûe dans un autre sol, la nôtre. 
Ses enfants sont nombreux; cependant, ô merveille! L'hymen est inconnu de la pudique abeille: Ignorant ses plaisirs ainsi que ses douleurs, Elle adopte des vers éclos du sein des fleurs, De jeunes citoyens repeuple son empire, Et place un roi nouveau dans ses palais de cire: Aussi, quoique le sort, avare de ses jours, Au septième printemps en termine le cours, Sa race est immortelle; et, sous de nouveaux maîtres, D'innombrables enfants remplacent leurs ancêtres. Plus d'une fois aussi, sur des cailloux tranchants Elle brise son aile en parcourant les champs, Et meurt sous son fardeau, volontaire victime: Tant du miel et des fleurs le noble amour l'anime! Quel peuple de l'Asie honore autant son roi ? Tandis qu'il est vivant, tout suit la même loi : Est-il mort? Ce n'est plus que discorde civile; On pille les trésors, on démolit la ville:

C'est l'âme des sujets, l'objet de leur amour ; Ils entourent son trône, et composent sa cour, L'escortent au combat, le portent sur leurs ailes, Et meurent noblement pour venger ses querelles. Frappés de ces grands traits, des sages ont pensé Qu'un céleste rayon dans leur sein fut versé.

Virgile, Géorgiques, op. cit., v. 197-220. 